\title{
Višegodišnja istraživanja biljno-hranidbenog kapaciteta tla metodom folijarne dijagnoze u voćnjacima Međimurja
}

\author{
Several-Year Investigation of Plant-Feeding Capacity of Soil \\ in Orchards of Međimurje
}

\section{Miljković}

\section{SAŽETAK}

U novije vrijeme kontrola biljno-hranidbenog kapaciteta tla u voćnjacima obavlja se metodom folijarne dijagnoze, jer se smatra pouzdanijom od pedoloških analiza. U radu se iznose rezultati višegodišnjih istraživanja koncentracije $\mathrm{N}, \mathrm{P}, \mathrm{K}, \mathrm{Ca}$ i $\mathrm{Mg}$, sume i ravnoteže kationa. Istraživanja su provedena u Donjem Međimurju u voćnjacima Nedelišće, Čehovec i Cirkovljan. Voćnjaci su podignuti na seriji aluvijalnih tala. U voćnjaku Nedelišće istraživanja su provedena na sortama Starkrimson, Golden Delicious, Idared i Golden Spur. U voćnjaku Čehovec su istraživanja obavljena na sortama Wellspur Delicious, Golden Spur, Golden Delicious i Idared, a u voćnjaku Cirkovljan na sortama Golden Delicious, Idared, Melrose i James Grieve. Prema kriterijima što ih predlažu istraživači Bould (1966.), Fiedler (1970.), Gruppe (1960.), Lalatta (1986.), Kenworthy (1963.) i drugi jabuke su dobro opskrbljene biogenim elementima. Veće variranje utvrđeno je u koncentraciji N, K i Ca. Genetske, odnosno sortne specifičnosti odrazile su se na koncentraciju $\mathrm{N}, \mathrm{K}, \mathrm{i} \mathrm{Ca}$, dok je razina $\mathrm{P}$ i $\mathrm{Mg}$ uglavnom podjednaka u svih sorti. U voćnjaku Nedelišće signifikantno više N i K sadrži lišće Starkrimsona od sorti Golden Spur, Golden Delicious i Idared. Signifikantno manja koncentracija N utvrđena je u lišću sorte Idared od ostale tri sorte. Signifikantno više Ca sadrži lišće Golden Deliciousa i Golden Spura od Idareda i Starkrimsona. U voćnjaku Čehovec signifikantno više N sadrži lišće Golden Deliciousa od sorti Golden Spur, Wellspur Delicious i Idared. Signifikantno više Ca sadrži lišće Golden Deliciousa i Golden Spura od Wellspur Deliciousa i Idareda. Signifikantno manje K sadrži lišće Idareda od ostale tri sorte. U voćnjaku Cirkovljan signifikantno više $\mathrm{N}$, a manje $\mathrm{Ca}$ sadrži lišće sorte James Grieve, od sorti Idared, Golden Delicious i Melrose. Najveća koncentracija K utvrđena je u lišću Golden Deliciousa, a najmanja u lišću sorte Idared. Razlika je statistički opravdana u odnosu na sorte Melorese i James Grieve.

Ustanovljena je podudarnost rezultata $s$ našim ranijim istraživanjima genetske specifičnosti mineralne ishrane sorti Golden Delicious, Idared i Starkrimson, koja su provedena u plantažama na pseudogleju (Dugo Selo, Donja Zelina, Katoličko Selište) u Posavini i Moslavini (Anić Jelka i Miljković I.; 1994.) i u plantaži Borinci na eutričnom smeđem tlu na karbonatnom lesu u Slavoniji (Miljković I. i Vrsaljko A.; 2009.).

Ključne riječi: jabuka, sorte, folijarna dijagnoza, genetske specifičnosti 


\begin{abstract}
In recent years, control of the soli plant-feeding capacity in orchards has been performed by the method of foliar diagnosis, because it is considered more reliable than soil analysis. The paper presents the results of several years of research on concentration of $\mathrm{N}, \mathrm{P}, \mathrm{K}, \mathrm{Ca}$ and $\mathrm{Mg}$, and the sum of cations and cation balance. Investigations were carried out in Donje Međimurje in orchards Nedelišće, Čehovec and Cirkovljan. Orchards were raised on a series of alluvial soils. In the orchard Nedelišće research was carried out on the varieties: Starkrimson, Golden Delicious, Idared and Golden Spur. In the orchard Čehovec research was carried out on varieties: Wellspur Delicious, Golden Spur, Golden Delicious and Idared, and in the orchard Cirkovljan on the varieties: Golden Delicious, Idared, Melrose and James Grieve. According to the criteria put forward by the researchers Bould (1966), Fiedler (1970), Grouppe (1960), Lalatta (1986), Kenworthy (1963) and others, apples are well supplied with biogenic elements. Larger variations were found between the concentrations of $\mathrm{N}, \mathrm{K}$ and $\mathrm{Ca}$. Genetic or varietal specifics are reflected in the concentration of $\mathrm{N}, \mathrm{K}$ and $\mathrm{Ca}$, while $\mathrm{Mg}$ and $\mathrm{P}$ levels are generally similar in all varieties. In the orchard Nedelišće there is significantly higher concentration of $\mathrm{N}$ and $\mathrm{K}$ in the leaves of Starkrimson than in varieties Golden Spur, Golden Delicious and Idared. A significantly lower concentration of $\mathrm{N}$ was found in the leaves of Idared than in other three varieties. Significantly higher concentration of $\mathrm{Ca}$ was found in the leaves of Golden Delicious and Golden Spur than in Idared and Starkrimson. In the orchard Čehovec significantly higher concentration of $\mathrm{N}$ were found in the leaves of Golden Delicious than in varieties Golden Spur, Wellspur Delicious and Idared. Significantly higher concentration of $\mathrm{Ca}$ was found in the leaves of Golden Delicious and Golden Spur than in Wellspur Delicious and Idared. The leaves of Idared contained significantly lower concentration of $\mathrm{K}$ than other three varieties. In the orchard Cirkovljan significantly higher concentration of $\mathrm{N}$ and lower concentration of $\mathrm{Ca}$ were found in the leaves of the variety James Grieve than in varieties Idared, Golden Delicious and Melrose. The highest concentration of $\mathrm{K}$ was found in the leaves of Golden Delicious, and the lowest in the leaves of Idared. The difference was statistically significant compared to the varieties Melorese and James Grieve.

The compliance with the results from our previous studies of genetic specificity of mineral nutrition was established for varieties Golden Delicious, Idared and Starkrimson in plantations on pseudogley soil (Dugo Selo, Donja Zelina, Katoličko Selište) in Posavina and Moslavina (Anić Jelka and Miljković I.; 1994) and the plantation Borinci on eutric brown soil on calcareous loess in Slavonia (Miljković I. and Vrsaljko A.; 2009).
\end{abstract}

Key words: apple, variety, foliar diagnosis, genetic specificities 


\section{PREGLED LITERATURE}

Kontrola biljno - hranidbenog kapaciteta tla u voćnjacima pridonosi boljem poznavanju složene problematike ishrane voćaka. U novije vrijeme kontrola se obavlja pretežno metodom folijarne analize, jer se smatra pouzdanijom od pedoloških analiza (Weissenbom 1956., Paulsen 1959., 1962., Bould 1966., Fiedler 1970., Lalatta 1986., Anić i Miljković 1994., Miljković i Vrsaljko 2009. i drugi.)

No, poznato je da na koncentraciju biogenih elemenata u lišću jabuke utječe velik broj faktora, od kojih kao važnije spominjemo sljedeće: geografski položaj, klimatske prilike, sorte, podloge, međupodloge, starost stabala, stupanj rodnosti, sustav uzdržavanja plodnosti tla, odnosno agrotehnika, međuovisnost biogenih elemenata itd.

U istim ekologijskim uvjetima i uz istu agrotehniku javljaju se razlike pod utjecajem sorata ili podloga pa je potrebno istražiti stupanj tih razlika, odnosno stupanj utjecaja kako bi se preciznije interpretirali rezultati folijarne analize (Cobianchi i Faedi, 1986. i dugi). Naime, ustanovljeno je da se pravilnim izborom holobioze epibionta i hipobionta može osjetno pridonijeti boljem korištenju prirodne plodnosti tla. Sukladno tome u Hrvatskoj su za precizniju procjenu adekvatne gnojidbe do danas provedena istraživanja utjecaja sorte na mineralni sastav lišća jabuka na pseudogleju (Anić i Miljković 1994), crvenici (Miljković i Jemrić 1996), i na eutričnom smeđem tlu na karbonatnom lesu (Miljković i Vrsaljko 2009.).

O utjecaju sorte na kemijski sastav lišća jabuke među prvima nas izvještavaju Batjera i Magens (1938), koji su u voćnjacima SAD-a proveli opsežna istraživanja. Naime, oni su utvrdili razlike u koncentraciji kalija u lišću između pojedinih sorata. Na te razlike nisu utjecale samo klimatske prilike, kao što se prije mislilo već i genetske specifičnosti sorata. Walker i Masson (1960) su također utvrdili da je lišće četiriju sorta jabuka sadržavalo različite koncentracije: dušika, fosfora i kalija i da su te razlike signifikantne. No najviše podataka o razlikama između koncentracije biogenih elemenata u lišću pojedinih sorti jabuka iznose Gruppe (1952., 1955., 1960.), Emert (1954.), Fiedler (1963.), Delver (1986. cit. Bergmann 1988.), Lalatta (1986.), Cobianchi i Faedi (1986.), a u Hrvatskoj Anić i Miljković (1994.), Miljković i Jemrić (1996.), Miljković i Vrsaljko (2009.) Velik broj istraživača iznosi podatke o razlikama u koncentraciji biogenih elemenata u lišću jabuke unutar iste sorte pod utjecajem podloge. Razlike pod utjecajem podloge utvrdili su Gruppe (1954.), Tuckey et al. (1962.), Award i Kentworthy (1963.), Witfield (1964.), 
Schneider et al. (1978.), Cobianchi i Faedi (1986.) i drugi. Kod jabuke su Cobianchi i Faedi (1986.) utvrdili da i međupodloga može odraziti utjecaj na razinu mineralnih elemenata u lišću sorata. Zanimljivo je istaknuti da i pojedine sorte odražavaju i specifične zahtjeve spram vrsti i količini gnojiva, kako nas na osnovi sustavnih istraživanja izvještava Mantinger (1986.). Napomenimo još da od svojstava tla najveći utjecaj na koncentraciju biogenih elemenata i odnos među njima ima reakcija tla. Tako su utvrđene posebno velike razlike $\mathrm{u}$ koncentraciji kalija u lišću jabuka za istu sortu uzgajanu u istom području na karbonatnom slabo alkalnom tlu i neutralnom odnosno slabo kiselom tlu (Miljković 1979.).

\section{OBJEKT ISTRAŽIVANJA I METODIKA RADA}

Na području Međimurja, gdje su klimatske prilike povoljne za uzgoj jabuka, veća prostranstva zauzimaju aluvijalna tla, na kojima su podignuti suvremeni intenzivni nasadi. Istraživanja biljno - hranidbenog kapaciteta tla metodom folijarne dijagnoze provedena su tijekom četiriju godina u voćnjacima: Nedelišće, Čehovec i Cirkovljan u Međimurju. U voćnjaku Nedelišće istraživanja su obavljena na sortama: Starkrimson, Golden Spur, Golden Delicious i Idared. U voćnjaku Čehovec istraživanjima su obuhvaćene sorte: Wellspur Delicious, Golden Spur, Golden Delicious i Idared, a u voćnjaku Cirkovljan sorte: Idared, Golden Delicious, Melrose i James Grieve. Istraživanja su provedena na dobro razvijenim stablima sorti na istoj podlozi, a u razdoblju pune rodnosti. Uzgojni oblik je vretenasti grm.

Uzorci lišća uzimani su potkraj srpnja kada je uslijedio zastoj rasta mladica, to jest $\mathrm{u}$ vrijeme kada dolazi do stabilizacije hraniva u lišću. Za svaku je sortu slučajnim izborom odabrano po 6 stabala, a sa svakog je stabla uzet po jedan uzorak lišća. Lišće je uzimano sa središnjeg perifernog dijela krošnje i to sa srednje razvijenih nerodnih izbojaka. Kemijska analiza lišća obuhvatila je količinu: dušika $(\mathrm{N})$, fosfora $(\mathrm{P})$, kalija $(\mathrm{K})$, kalcija $(\mathrm{Ca})$ i magnezija $(\mathrm{Mg})$. U voćnjaku Nedelišće izneseni su podaci za sumu kationa $(\mathrm{K}+\mathrm{Ca}+\mathrm{Mg})$, ravnotežu kationa $(\mathrm{Ca}+\mathrm{Mg} / \mathrm{k})$ i intenzitet ishrane $(\mathrm{N}+\mathrm{P}+\mathrm{K}+\mathrm{Ca}+\mathrm{Mg})$. Razina dušika utvrđena je po metodi Kjeldahla, fosfora i kalija spektrofotometrijom, odnosno flamenfotometrijski, a kalcija i magnezija pomoću atomskog apsorpcijskog spektrofotometra. Rezultati istraživanja koncentracije N, P, K, Ca i Mg obrađeni su analizom varijance i Duncan-ovim testom uz $\mathrm{P} \leq 0.05$. 


\section{REZULTATI ISTRAŽIVANJA}

$\mathrm{Na}$ tablici 1. izneseni su rezultati četverogodišnjih istraživanja koncentracije: $\mathrm{N}, \mathrm{P}, \mathrm{K}, \mathrm{Ca}, \mathrm{i} \mathrm{Mg}$ za sve sorte u voćnjaku Nedelišće, a na tablici 2. sumarno po sortama. U voćnjaku su sve sorte dobro opskrbljene dušikom, fosforom, kalijem, kalcijem i magnezijem suma kationa i ravnoteža kationa je dobra, kao i intenzitet ishrane.

Tablica 1.: Mineralni sastav lišća jabuke u voćnjaku Nedelišće

Table 1: Mineral composition of apple leaves in the orchard Nedelišće

\begin{tabular}{|c|c|c|c|c|c|c|c|c|}
\hline Godina & $\mathrm{N}$ & $\mathrm{P}$ & $\mathrm{K}$ & $\mathrm{Ca}$ & $\mathrm{Mg}$ & $\mathrm{N}+\mathrm{P}+\mathrm{K}$ & $\mathrm{K}+\mathrm{Ca}+\mathrm{Mg}$ & $(\mathrm{Ca}+\mathrm{Mg}) / \mathrm{K}$ \\
\hline 1977 & 2,97 & 0,26 & 1,51 & 1,93 & 0,36 & 4,74 & 3,81 & 1,51 \\
\hline 1978 & 2,84 & 0,19 & 1,39 & 1,65 & 0,20 & 4,42 & 3,24 & 1,35 \\
\hline 1979 & 2,77 & 0,19 & 1,74 & 1,78 & 0,29 & 4,70 & 3,81 & 1,20 \\
\hline 1980 & 2,77 & 0,23 & 1,60 & 2,02 & 0,30 & 4,60 & 3,92 & 1,39 \\
\hline Prosjek & 2,84 & 0,22 & 1,56 & 1,84 & 0,29 & 4,61 & 3,70 & 1,36 \\
\hline
\end{tabular}

Tablica 2.: Genetske specifičnosti mineralne ishrane sorti jabuke u voćnjaku Nedelišće

Table 2: Genetic specificity of mineral nutrition apple cultivars in the orchard Nedelišće

\begin{tabular}{|c|c|c|c|c|c|c|c|c|}
\hline $\begin{array}{c}\text { Sorta - } \\
\text { Cultivar }\end{array}$ & $\mathrm{N} \%$ & $\mathrm{P} \%$ & $\mathrm{~K} \%$ & $\mathrm{Ca} \%$ & $\begin{array}{c}\mathrm{Mg} \\
\%\end{array}$ & $\begin{array}{c}\mathrm{K}+\mathrm{Ca} \\
+\mathrm{Mg}\end{array}$ & $\mathrm{N}+\mathrm{P}+\mathrm{K}+\mathrm{Ca}+\mathrm{Mg}$ & $\mathrm{N} / \mathrm{K}$ \\
\hline $\begin{array}{c}\text { Starkrims } \\
\text { on }\end{array}$ & $3,11 \mathrm{a}$ & 0,29 & $1,83 \mathrm{a}$ & $1,70 \mathrm{~b}$ & 0,23 & 3,76 & 7,16 & 1,70 \\
\hline $\begin{array}{c}\text { Golden } \\
\text { Spur }\end{array}$ & $2,72 \mathrm{~b}$ & 0,24 & $1,50 \mathrm{~b}$ & $2,37 \mathrm{a}$ & 0,36 & 4,22 & 7,18 & 1,81 \\
\hline $\begin{array}{c}\text { Golden } \\
\text { Delicious }\end{array}$ & $2,81 \mathrm{~b}$ & 0,28 & $1,47 \mathrm{~b}$ & $2,29 \mathrm{a}$ & 0,36 & 4,12 & 7,15 & 1,91 \\
\hline Idared & $2,47 \mathrm{c}$ & 0,21 & $1,52 \mathrm{~b}$ & $1,82 \mathrm{~b}$ & 0,24 & 3,58 & 6,26 & 1,63 \\
\hline Prosjek & 2,78 & 0,25 & 1,58 & 2,04 & 0,30 & 3,92 & 6,99 & 1,76 \\
\hline
\end{tabular}


Na tablici 2. vidimo da u voćnjaku Nedelišće više dušika sadrži lišće sorte Starkrimson od sorti Golden Delicious, Golden Spur i Idared. Razlika je statistički opravdana. Najmanje dušika sadrži lišće sorte Idared. Ustanovljena je statistički opravdana razlika za koncentraciju dušika između sorte Idared i ostale tri sorte. Koncentracija kalija najveća je u lišću sorte Starkrimson. Razlika u koncentraciji kalija signifikantna je između Starkrimsona i ostale tri sorte. Utvrđena je signifikantno veća koncentracija kalcija u lišću sorti Golden Delicious i Golden Spur u odnosu na sorte Starkrimson i Idared. Koncentracija fosfora i magnezija bila je podjednaka u lišću istraživanih sorti.

Na tablici 3. izneseni su rezultati istraživanja u voćnjaku Čehovec.

Tablica 3.: Genetske specifičnosti mineralne ishrane sorti jabuka u voćnjaku Čehovec

Table 3: Genetic specificity of mineral nutrition apple cultivar in the orchard Čehovec

\begin{tabular}{|c|c|c|c|c|c|}
\hline $\begin{array}{c}\text { Sorta - } \\
\text { Cultivar }\end{array}$ & $\mathrm{N} \%$ & $\mathrm{P} \%$ & $\mathrm{~K} \%$ & $\mathrm{Ca} \%$ & $\mathrm{Mg} \%$ \\
\hline $\begin{array}{c}\text { Wellspur } \\
\text { Delicious }\end{array}$ & $2,28 \mathrm{c}$ & 0,23 & $1,62 \mathrm{a}$ & $1,65 \mathrm{~b}$ & 0,36 \\
\hline Golden Spur & $2,47 \mathrm{~b}$ & 0,22 & $1,62 \mathrm{a}$ & $2,04 \mathrm{a}$ & 0,37 \\
\hline Idared & $2,48 \mathrm{~b}$ & 0,22 & $1,24 \mathrm{c}$ & $1,78 \mathrm{~b}$ & 0,26 \\
\hline $\begin{array}{c}\text { Golden } \\
\text { Delicious }\end{array}$ & $2,84 \mathrm{a}$ & 0,22 & $1,41 \mathrm{~b}$ & $2,47 \mathrm{a}$ & 0,38 \\
\hline
\end{tabular}

Na tablici vidimo da signifikantno više dušika sadrži lišće sorte Golden Delicious od sorti Golden Spur, Wellspur Delicious i Idared. Signifikantna je razlika između sorte Golden Delicious i ostale tri sorte. Najnižu koncentraciju dušika sadržavalo je lišće sorte Wellspur Delicious. Razlika u koncentraciji dušika između Wellspur Deliciousa i ostale tri sorte je statistički opravdana. Signifikantno manje kalija sadrži lišće sorte Idared, od sorti Golden Delicious, Wellspur Delicious i Golden Spur. Signifikantno manje kalija sadržavalo je lišće sorte Golden Delicious od ostale tri sorte. Signifikantno više kalcija sadržavalo je lišće sorti Golden Delicious i Golden Spur od lišća sorti Idared i Wellspur Delicious. Među sortama nisu utvrđene signifikantne razlike u koncentraciji fosfora i magnezija.

Rezultati istraživanja u voćnjaku Cirkovljan izneseni su na tablici 4. 
Tablica 4.: Genetske-sortne specifičnosti ishrane u voćnjaku Cirkovljan

Table 4: Mineral composition of apple leaves in the orchard Cirkovljan

\begin{tabular}{|c|c|c|c|c|c|}
\hline $\begin{array}{c}\text { Sorta - } \\
\text { Cultivar }\end{array}$ & $\mathrm{N} \%$ & $\mathrm{P} \%$ & $\mathrm{~K} \%$ & $\mathrm{Ca} \%$ & $\mathrm{Mg} \%$ \\
\hline Idared & $3,01 \mathrm{~b}$ & 0,23 & $1,19 \mathrm{~b}$ & $1,89 \mathrm{a}$ & 0,32 \\
\hline Melrose & $3,03 \mathrm{~b}$ & 0,27 & $1,56 \mathrm{a}$ & $1,74 \mathrm{~b}$ & 0,30 \\
\hline James Grieve & $3,30 \mathrm{a}$ & 0,30 & $1,56 \mathrm{a}$ & $1,63 \mathrm{~b}$ & 0,38 \\
\hline $\begin{array}{c}\text { Golden } \\
\text { Delicious }\end{array}$ & $3,02 \mathrm{~b}$ & 0,25 & $1,60 \mathrm{a}$ & $1,93 \mathrm{a}$ & 0,31 \\
\hline
\end{tabular}

U voćnjaku Cirkovljan signifikantno više dušika a manje kalcija sadrži lišće ljetne sorte James Grieve od sorti: Idared, Golden Delicious i Melrose. Najveća koncentracija kalija utvrđena je u lišću sorte Golden Delicious, a najmanja u lišću sorte Idared. Utvrđena je statistički opravdana razlika za koncentraciju kalija između sorte Idared i sorti: Melrose, James Grieve i Golden Delicious.

\section{ZAKLJUČCI}

Prema kriterijima što ih predlažu istraživači: Bould (1966.), Fiedler (1970.), Gruppe (1969., Lalatta (1986.), Kennworty (1963.) i drugi u voćnjacima Donjeg Međimurja jabuke su dobro opskrbljene biogenim elementima.

Veće variranje utvrđeno je u koncentraciji $\mathrm{N}, \mathrm{K}$ i Ca, dok je razina $\mathrm{P}$ i $\mathrm{Mg}$ uglavnom podjednaka kod svih sorti. Utvrđene su genetske, odnosno sortne specifičnosti mineralne ishrane. Ustanovljena je podudarnost rezultata naših ranijih istraživanja genetske specifičnosti mineralne ishrane sorti Golden Delicious, Idared i Starkrimson koja smo proveli u plantažama na pseudogleju (Donja Zelina, Dugo Selo i Katoličko Selište) u Posavini i Moslavini (Anić J., Miljković I., 1994.) i u plantaži Borinci na eutričnom smeđem tlu na karbonatnom lesu (Miljković I., Vrsaljko A., 2009.).

\section{LITERATURA}

ANIĆ J., MILJKOVIĆ I., (1994.): Genetske specifičnosti mineralne ishrane sorata jabuka. Agronomski glasnik 1-2, 1-12.

ATKINSON, D., SANDRA A. WILSON, (1979.): The growth and distribution of fruit tree roots: some consequences for nutrient uptake. Mineral nutrition of fruit trees, 137-150., Butterworths, London-Boston-Sydney-WellingtonDurban-Toronto. 
AWARD M. M., KENWORTHY A. L., (1963.): Clonal Rootstock, Scion Variety and Time of Sampling Influences in Apple Leaf Composition. Proc. Amer. Soc. Hort., Sci. vol. 83., 68-73.

BATJER L. P., MAGNES J. R., (1938.): Potassium content of leaves from commercial apple orchards. Proc. Amer. Soc. Hort. Sci. 36., 197-201.

BERGMANN W., (1988.): Ernahrungsstorungen bei Kulturpflanzen. Gustav Fischer Verlag, Jena.

BOULD C, (1966.): Leaf analysis of deciduous trees. In Nutrition of fruit Crops. (Ed. by N.F. Childers), pp 651-684. New Jersey, Horticultural Publications, Rutgers University.

BÜNEMANN O., (1959.): Über beziehungen zwischen Qualitat und Haltbarkeit von Apfeln in Abhangigkeit von Mineralsoffgehalt des Bodens und der Blatter I., Gartenbauwissenschaft, 24(6), 177-201.

BÜNEMANN G., (1979.): Mineral nutrition and fruit quality of temperature zone fruit trees. Mineral nutrition of fruit trees, Butterworths, LondonBoston.

COBIANCHI D., FAEDI W., (1968.): Influenza della combinacione d'innesto sulla nutrizione minerale del melo. La fertilizzazione delle piante da frutto, Atti del Convegno-Verona 203-215.

DELVER P., (1986.): Proefostation voor de Fruitteelt. Wilheminadorp, Niederlande, Personl. Mitt, von 4/5, 11.

EMMERT F. H., (1954.): The influence of variety trees age und mulch on the nutritional composition of apple leaves, Proc. Amer. Soc. Hort. Sci. 64., 914.

FIEDLER W., (1963.): Abschlussbericht zur Forschungsarbeit "Durchfuhrung einer Eshebung Uber die Dungung in Obstbau unter verschiedenen Standortbedingungen", Dresden-Pillniz, Inst. Obst.u. Zierpflanzenbau Dtsch. Abad. Landwirstch. Wiss., Berlin, Plant-Nr.: 1701, 14h/3-15.

FIEDLER W., (1970.): Listovoj analiz v plodovodstve, Moskva.

GORINI F., (1986.): Relazione tra fertilizzazione, qualita e conservabilita, La fertilizzazione delle piante da frutto, Atti del Convegno, Verona, 119-150. 
GRUPPE W., (1954.): Vergleichende Blatt-und Badenuntersuchungen in Apfelplanta gen und baumschulen unter besonderer Beriicksichtigung van Kalium und Magnezium I. Metodolo-gische Untersuchungen zur Blattanalyse, Gartenbauwissenschaft, 19 (1) 419-439.

GRUPPE W., (1955.): Vergleichende Blutt-und Badenuntersuchungen in Apfelplantagen und baumschulen under besonderer Berucksichtigung von Kalium und Magnesium III. Das Auftreten in Nordwestdeutchland (Erhebungsutersuchungen), Gartenbauwissenschaft, (20) 3-29.

GRUPPE W., (1960.): Die Bedeutung der Blattanalyse fiir die Diingung im Obstbau, Erwerb-sobstbau, 2., 198-201., 216-222.

GRUPPE W., (1960.): Zur Beurteilung und Behebung von Magnesium-mangel beim Apfel, Erwerbs obstbau 2., 51 -53.

LALATTA F., (1986.): Metodi ed interpretazione delle analisi fogliari., La fertilizzazione delle piante da frutto. Atti del Convegno, 49-75., Verona.

MANTINGER H., (1968.): Influenza della concimazione minerale su alcune varieta di melo in una prova flurionnale, La fertilizzazione delle piante da frutto. Atti del Convegno, Verona, 151 -169.

MILJKOVIĆ I., (1984.): Bonitiranje zemljista kulture vocaka. Agronomski glasnik br. 6, 881-919.

MILJKOVIĆ I., JEMRIĆ T., (1997.): Genetic specificity of mineral nutrition of summer apple cultivars. Acta Horticulturae No. 447, 113-118.

MILJKOVIĆ I., (1979.): Kloroza jabuka u Slavoniji. Jug. voćarstvo 44-45, pp. 43-56

MILJKOVIĆ I., (1997.): Pomoekologija Slavonije i Baranje. Agronomski glasnik 5-6, 477-493.

MILJKOVIĆ I., VRSALJKO A., (2009.): Genetske specifičnosti mineralne ishrane sorata jabuka u plantaži Borinci. Pomologia Croatica 1-2., 3-15.

POULSEN E., (1959.): Kan den kemiske planteanalyse anvendes som indikator for planternes ernaeringhitil stand. Horticultura (Kobenhaven), 21-26.

POULSEN E., (1962.): Kand bladanalyser anvendes sone indikator for frugtteernes Kvaastofsosyng?, Ervervsfrugtarleren 28., 191-194. 
SEIZ P., (1963.): Ergebnisse eines 6 jahrigen Dungungsversuches zu Apfeln. Erwerbsobstbau 10., 185-187.

SCHNEIDER, G.W., CHAPLIN C.E., AND MARTIN D.C., (1978.): Effects of apple rootstocks, tree spacing and cultivar on fruit yield, and foliar mineral composition. J. Amer. Soc. Hort. Sci. 103., 230-232.

STOLLE G., (1956.): Einjiihring Untersuchungen iiber den Nahrstoffgehault der Blatter von Apfel-baumen verschiedener Sorten. Unterlagen und Standorte, Arch. Gartenbau 4, 151- 163.

TUCKEY H.B., LANGSTON R., CLINE R.A., (1962.): Influence of rootstock, badystock, and interstock on the nutrient content of apple foliage. Proc. Amer. Soc. Hort. Sci. 80., 73-78.

VRSALJKO A., (1995.): Genetske specifičnosti mineralne ishrane sorti bajama. Pomologia Croatica, 1-2, 89-101.

WALKER D. R., MASON D.D., (1960.): Nutritional status of apple orchards in North Carolina. Proc. Amer. Soc. Hort. Sci. 75., 22-31.

WEISSENBORN K., (1956.): Einige Hinweise fiir die Boden und Blattuntersuchung. Mitt. Obstbauversuchsringes Alten Landes, 11., 208213.

WHILFIELD A. B., (1964.): A note on the concentration of major nutrient elements in Cox's orange pippin apples. Rep. E. Mailing Res. Sta. for 1963., 148-149.

\section{Adresa autora - Author's address:}

Prof. dr. sc. Ivo Miljković

10000 Zagreb, Čazmanska 2 